\title{
Genetic Variability and Microdistribution of Triatoma infestans Genotypes and Trypanosoma cruzi Clones in Arequipa Region (Peru)
}

\author{
Simone F Brenière/ ${ }^{+}$, Jenny Lopez*, Fernando Vargas, \\ Christian Barnabé
}

\begin{abstract}
UMR CNRS/ORSTOM no 9926: “Génétique Moléculaire des Parasites et des Vecteurs”, ORSTOM, BP 5045,
\end{abstract} 34032 Montpellier Cedex 01, France *Universidad National de San Agustin, Casilla 1365, Arequipa, Peru

The genetic variability of Triatoma infestans and Trypanosoma cruzi populations was studied by isoenzyme analysis in two distinct areas of Arequipa province (Peru); one, Santa Rita de Siguas, being an endemic area for Chagas' disease, the second, Arequipa, recently infected. Analysis of T. infestans genetic variability indicates, (i) temporal stability of genotypes found in Santa Rita de Siguas, (ii) high genetic differences between Arequipa and Santa Rita de Siguas populations suggesting minor contact between them, (iii) multiple origin of the T. infestans population in Arequipa, and (iv) poor dispersal capacity of T. infestans: the panmictic unit could be reduce to a house. Parasite isoenzyme analysis was performed in 29 Peruvian stocks of T. cruzi, mainly isolated from bugs taken in a single locality, Santa Rita de Siguas. The results show, (i) a high genetic polymorphism, (ii) nine different multilocus genotypes were detected and clustered in two different clades, (iii) most of the parasite isolates pertained to one of the clade and were genetically similar to those analyzed 12 years before. This sample allowed the study of the mating system of $\mathrm{T}$. cruzi in strict sympatic conditions and gave more strength to the hypothesis of the clonal structure of T. cruzi populations.

Key words: population genetics - Triatoma infestans - Trypanosoma cruzi - Chagas' disease - clones

The extent of genetic variation and population structure in Triatoma infestans, the principal vectors of Chagas' disease in South America, were studied in Bolivian, Peruvian and Brazilian populations by isoenzyme analysis (Dujardin \& Tibayrenc 1985 a,b, Dujardin et al. 1987). The results show: (i) a relatively low rate of variability when compared with most other insects (3 variable loci among 19); (ii) an apparent absence of speciation between geographically separate populations and between domestic and sylvatic ones; (iii) free gene flow within $T$. infestans from a given locality and sometimes between neighboring localities. In Peru, genetic of $T$. infestans populations is poorly documented.

Trypanosoma cruzi, the causative agent of Chagas' disease, is present in nature as populations of "natural clones " as demonstrated by popula-

Work supported by ORSTOM (Institut Français de Recherche Scientifique pour le Développement en Coopération).

${ }^{+}$Corresponding author. Present address: ORSTOM Mission Bolivia, Casilla 9214, La Paz, Bolivia. Fax : +591-2-39.1854

Received 8 May 1996

Accepted 16 October 1996 tion genetic studies; these natural clones appear to be evolving over time and dispersing over geographic locations without genetic exchange between organisms, thus maintaining genetically similar populations (Tibayrenc \& Ayala 1988). Statistical tests exploring the reproductive system of population (segregation within a locus and recombination among loci) were developed in order to standardize the genetic analysis (Tibayrenc et al. 1990). Lack of evidence for segregation and recombination, indicate that genetic exchanges are limited and therefore that the population could present a clonal structure. The goals of this work were firstly, to study the epidemiological implications of the genetic variability of the $T$. infestans populations, second to analyze the genetic variability and mating system of $T$. cruzi populations in sympatric conditions, finally, to compare the present results with those obtained 12 years before (Brenière et al. 1985) and analyze the micro distribution of $T$. infestans genotypes and T. cruzi clones in a single locality.

\section{MATERIALS AND METHODS}

Origins of T. infestans insects and T. cruzi stocks - Table I summarizes the numbers and origin of vectors and stocks of parasites. All of the insects were identified as T. infestans according to 
Lent and Wygodzinsky (1979). Eighty-three bugs were captured from 8 different houses in Santa Rita de Siguas locality, $85 \mathrm{~km}$ from Arequipa town (populations A to E). Population A grouped the insects from 4 different houses because of the low number of specimens. The other populations are from single houses and the maximum distance between houses is $1.6 \mathrm{~km}$. Populations $\mathrm{F}$ and $\mathrm{G}$ are from the neighborhood of Arequipa town, while population $\mathrm{H}$ is from laboratory colonies which originated from Arequipa. Twenty-three T. cruzi stocks were isolated from $T$. infestans taken in Santa Rita de Siguas, two other stocks were isolated from two different chagasic patients of Arequipa town by xenodiagnosis, and two more stocks originated from T. infestans taken in Moquegua department, Matalaque.

Isoenzyme analysis - For parasites and vectors, we used electrophoretic separation of isoenzymes on cellulose acetate plates (Helena, Beaumont, TX). The vector isoenzyme study was performed from thoraxic extracts of each individual (adult or nymphs) according to Dujardin et al. (1985a) procedures with slight modifications. A total of 10 enzyme systems were tested on a sample of 32 individuals: alfa - glycerophosphate dehydrogenase $(\alpha$ GPD, EC 1.1.1.8), glutamate oxaloacetic transaminase (GOT, EC 2.6.1.1), glucosephosphate isomerase, (GPI, EC 5.3.1.9), leucine aminopeptidase (LAP, EC 3.4.11.1), malate dehydrogenase (MDH, EC 1.1.1.37), malic enzyme (ME, EC 1.1.1.40), peptidases (substrates: L-leucyl-leucineleucine and L-leucyl-L-alanine) (PEP1 and 2, EC 3.4.11.11 and 3.4.11.13), 6-phosphogluconate dehydrogenase (6PGD, EC 1.1.1.44), and phosphoglucomutase (PGM, EC 2.7.5.1). The three enzyme systems previously described as variable in $T$. infestans (Dujardin et al. 1985a) were resolved from each individual (PGM, 6PGD and $\alpha$ GDH).

Parasites were isolated according to Tibayrenc et al. (1982) and cultured in LIT liquid medium. Parasites were harvested by centrifugation and pellets stored at $-70^{\circ} \mathrm{C}$. Before electrophoresis, pellets were mixed with an equal volume of enzyme stabilizer (Godfrey \& Kilgour 1976) and left on ice for $20 \mathrm{~min}$. They were then centrifuged at $11,000 \mathrm{~g}$ at $4^{\circ} \mathrm{C}$ for $10 \mathrm{~min}$. Supernatants were aliquoted and stored at $-70^{\circ} \mathrm{C}$ or used immediately. Two reference stocks named So34 cl4 and Mn, pertaining to natural clones 20 and 39 (see Tibayrenc \& Ayala 1988) were selected as controls. Electrophoresis was performed according to Ben Abderrazak et al. (1993) with slight modifications. Twelve different enzyme systems were surveyed: glutamate dehydrogenase NAD (GD1, EC 1.4.1.2), glutamate dehydrogenase NADP+ (GD2, EC 1.4.1.4) glutamate oxaloacetic transaminase (GOT,
EC 2.6.1.1), glucose 6-phospate dehydrogenase (G6PD, EC 1.1.1.49), glucosephosphate isomerase (GPI, EC 5.3.1.9), isocitrate dehydrogenase (IDH, EC 1.1.1.42), malate dehydrogenase (MDH, EC 1.1.1.37), malic enzyme (ME, EC 1.1.1.40) peptidases (substrates: L-leucyl-leucine-leucine and Lleucyl-L-alanine) (PEP1 and 2, EC 3.4.11.11 and EC 3.4.11.13), 6-phosphogluconate dehydrogenase (6PGD, EC 1.1.1.44) and phosphoglucomutase (PGM, EC 2.7.5.1).

Genetic variability - In vectors - To determine whether genetic exchange has been occurring in the studied populations, we used the (F) fixation index (Nei 1987) according to the formula: $F=$ $\left(4 \mathrm{n}_{11} \mathrm{n}_{22}-\mathrm{n}_{12}{ }^{2}\right) /\left(2 \mathrm{n}_{11}+\mathrm{n}_{12}\right)\left(2 \mathrm{n}_{22}+\mathrm{n}_{12}\right)$ with $\mathrm{n}_{11}$ and $n_{22}$ the number of homozygotes, and $n_{12}$ the number of heterozygotes. The deviation of $\mathrm{F}$ from 0 was tested by $\mathrm{X}^{2}=\mathrm{nF}^{2}$ with one degree of freedom, and $n=n_{11}+n_{12}+n_{22}$ (Nei 1987). We applied the test in the entire population and in subpopulations.

Analysis of spatial subdivision, was conducted by Nei's F statistics analysis (Nei 1987). The significance of the Fst (gene frequencies differences among populations) and Fis (fixation indices of individuals relative of subpopulations) values were calculated according to Bilton (1992). This test is not applicable when only two sub populations are compared and the Workman and Niswander (1970) statistic was applied to test the homogeneity in allelic frequencies (Pgm and 6Pgdh loci) between two populations.

In parasites - Population structure was explored by two set of statistical tests. The tests estimate deviations from random mating (segregation of alleles at given loci) and linkage disequilibrium (recombination of genotypes among loci). Departure from Hardy-Weinberg equilibrium (segregation within a locus) was tested by $\mathrm{X}^{2}$ test for expected values of $>2$. The recombination tests have been detailed elsewhere (Tibayrenc et al. 1990, 1991), together with the possible biases brought by geographical distance and natural selection. Test $\mathrm{d} 1$ relies upon a combinatory analysis, and gives the probability of sampling the most frequent genotype as many or more times than actually observed in a population. Test $\mathrm{d} 2$ measure the probability of observing as many or more individuals of any genotype as actually observed of the most common genotype. Test e gives the probability of observing as few or fewer different genotypes as found in the sample. Test $f$ estimates the probability of observing a linkage disequilibrium as high as actually found.

For estimation of phenetic divergence and clustering procedure, Jaccard's distance (Jaccard 1908) was used. It is estimated as follows: 


$$
\mathrm{D} \mathrm{j}=1-(\mathrm{C} / 2 \mathrm{~N}-\mathrm{C})
$$

where, $\mathrm{C}=$ number of bands common to both genotypes to be compared; $\mathrm{N}=$ total number of observed bands in the two compared genotypes. The UPGMA method (unweighted pair-group method with arithmetic averages, Sneath \& Sokal 1963) was used to cluster the zymodemes together according to their Jaccard's distances. Dendrogram was computed by using the software kindly communicated by Serres and Roux (1986).

The polymorphism rate $\mathrm{P}$, was determined by $\mathrm{p} / \mathrm{n}$ with $\mathrm{p}=$ number of variable loci and $n=$ number of studied loci.

We measure the clonal diversity in different populations by Whittam index (1989) :

$$
\mathrm{d}=\mathrm{n}\left(1-\Sigma \mathrm{Xi}^{2}\right) /(\mathrm{n}-1)
$$

with, $\mathrm{Xi}=$ frequency of each zymodeme and $\mathrm{n}=$ number of individuals.

\section{RESULTS}

Genetic variability of vectors - Enzymatic polymorphism: among 10 enzyme systems tested, 2 (ME and PEP1) made it possible to infer the activity of two different enzyme loci, consequently, the 10 enzyme systems corresponded to 12 putative loci. In the entire sample, only two loci appeared polymorphic, $P g m$ and $6 P g d h$ exhibiting patterns reported before (Dujardin et al. 1985 a,b). The proportion of polymorphic loci was 0.16. Eigh popu- lations were analyzed, 5 from a single locality (Santa Rita de Siguas), 2 from Arequipa town, and 1 from laboratory. Genotypes of the different populations are presented in Table I. The 6PGD enzyme system was variable only in bugs from Arequipa town, in natural populations and laboratory rearing.

Genetic structure of populations: departure from Hardy-Weinberg equilibrium was tested by the fixation index $(F)$ of Nei and the results are presented in Table II. Genotype frequencies (Pgm and $6 P g d h$ loci) of triatomines in the entire population, in Santa Rita de Siguas and in Arequipa ones were not significantly different from those expected for random mating population. Results of F-statistic (Table II) are suggestive of inbreeding and spatial partition among the seven natural populations from Arequipa and Santa Rita de Siguas (significant Fst). We also detected spatial partition among Santa Rita de Siguas populations which are from different houses (populations A, B, C, D, and E). When the population $\mathrm{B}$, composed of bugs taken in house no. 3 , is discarded from the analysis of Santa Rita de Siguas populations, spatial structuring disappeared. We observed differences in genotypic frequency between both natural populations from Arequipa (populations F and G) for only Pgm locus (Workman and Niswander test, $\mathrm{p}<0.01$ ).

Genetic variability of parasites - Among the 12 enzyme systems tested, 1 (ME) made it pos-

TABLE I

Origin of vectors and parasites from Arequipa province (Peru) and vector genotype

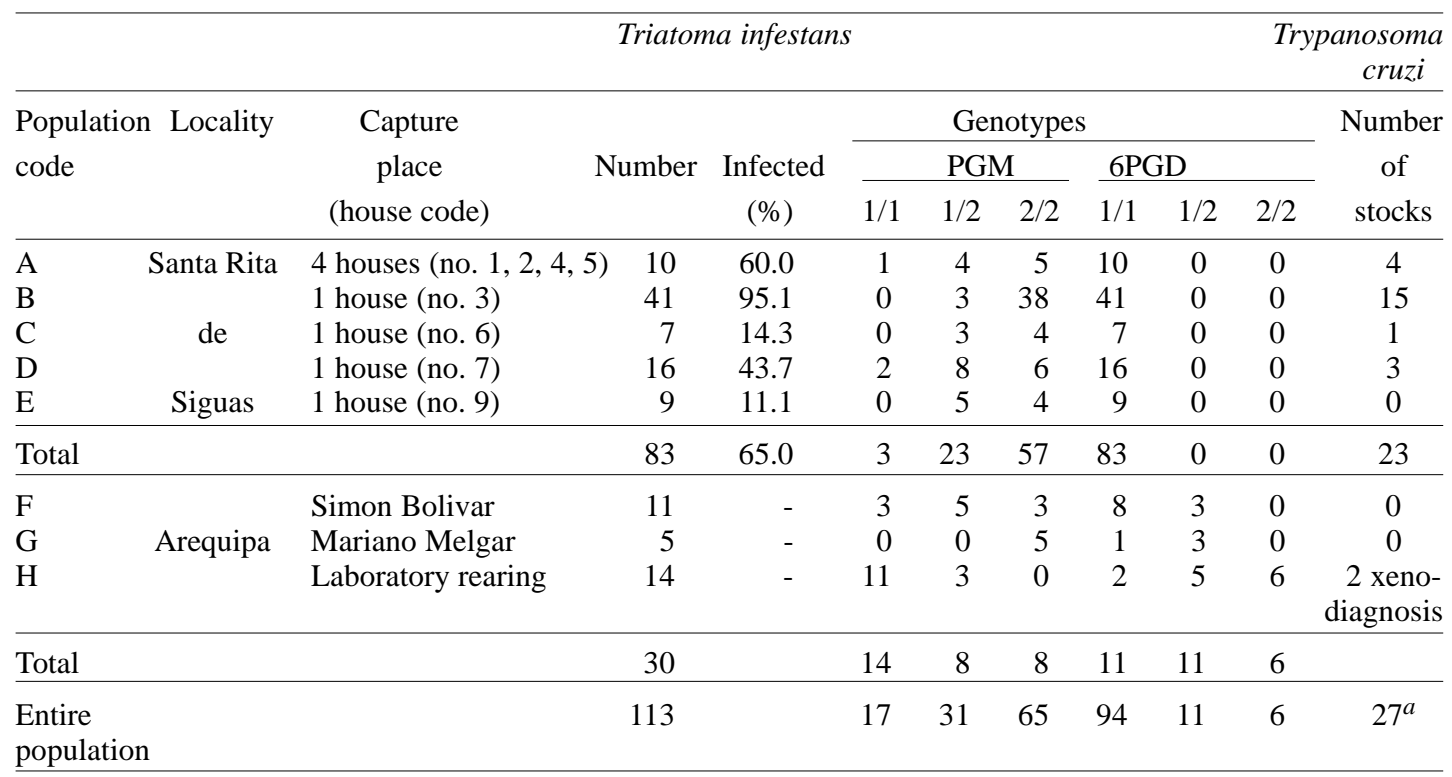

a: two additional T. cruzi stocks have been isolated from T. infestans captured in Matalaque locality of Moquegua province. 
TABLE II

Genetic variability of Triatoma infestans natural population

\begin{tabular}{|c|c|c|c|c|c|c|c|c|c|c|}
\hline \multirow{2}{*}{\multicolumn{3}{|c|}{$\begin{array}{l}\text { Compared } \\
\text { populations }\end{array}$}} & \multicolumn{2}{|c|}{ Fixation index } & \multicolumn{6}{|c|}{ F-Statistic } \\
\hline & & & & & \multicolumn{3}{|c|}{$P G M$} & \multicolumn{3}{|c|}{$6 P G D$} \\
\hline Origin & Code & Number & $P G M$ & $6 P G D$ & Fis & Fit & Fst & Fis & Fit & Fst \\
\hline $\begin{array}{l}\text { Santa Rita } \\
\text { de Siguas } \\
\text { and Arequip }\end{array}$ & $\begin{array}{c}\text { A, B, C, D, E, } \\
\text { F, G }\end{array}$ & 7 & 1.41 & 0.05 & -0.04 & 0.14 & $0.17^{b}$ & $-0.4^{b}$ & -0.004 & $0.28^{b}$ \\
\hline \multirow{3}{*}{$\begin{array}{l}\text { Santa Rita } \\
\text { de Siguas }\end{array}$} & $\mathrm{A}, \mathrm{B}, \mathrm{C}, \mathrm{D}, \mathrm{E}$ & 5 & 0.12 & - & -0.1 & 0.004 & $0.1^{a}$ & - & - & - \\
\hline & $\mathrm{A}, \mathrm{C}, \mathrm{D}, \mathrm{E}$ & 4 & 0.54 & - & -0.1 & -.04 & 0.05 & - & - & - \\
\hline & & & & & \multicolumn{6}{|c|}{$\begin{array}{l}\text { Workman and Niswander test } \\
\qquad \mathrm{X}^{2}\end{array}$} \\
\hline Arequipa & $\mathrm{F}, \mathrm{G}$ & 2 & 1.51 & 0.93 & & $7.62^{a}$ & & & 2.08 & \\
\hline
\end{tabular}

$a: \mathrm{p}<0.01 ; b: \mathrm{p}<0.001$

sible to infer the activity of two different enzyme loci. The locus which zone of activity had the fastest elecrophoretic migration was coded : " 1 ", while the other one was coded " 2 ". The 12 enzyme systems hence made it therefore possible to evidence the activity of 13 different genetic loci. Among them, 12 loci proved to be variable (polymorphism rate $=0.92)$. Genetic variability was interpreted when possible in terms of alleles, according to the hypothesis that $T$. cruzi is a diploid organism (Lanar et al. 1981, Tibayrenc et al. 1981). Nevertheless, at $P g m$ locus the patterns were too complex to be interpreted in terms of alleles. In this case, each distinct and reproducible pattern was considered as a distinct genotype, which precise allelic composition remained unknown (Fig. 1).

Nine distinct multilocus genotypes, or zymodemes, were detected of the 27 Peruvian $T$. cruzi stocks examined (Table III, Fig. 2). Two stocks evidenced at some loci a superposition of

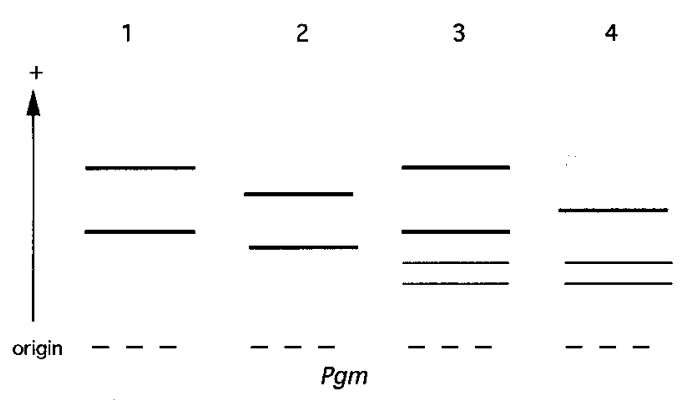

Fig. 1: non-allelic genotypes recorded at the Pgm locus. Slot 1: 1-4 phenotype, slot 2: 2-5 phenotype, slot 3:1-4-6-7 phenotype, slot 4: 3-6-7 phenotype. The bold band are intense bands.

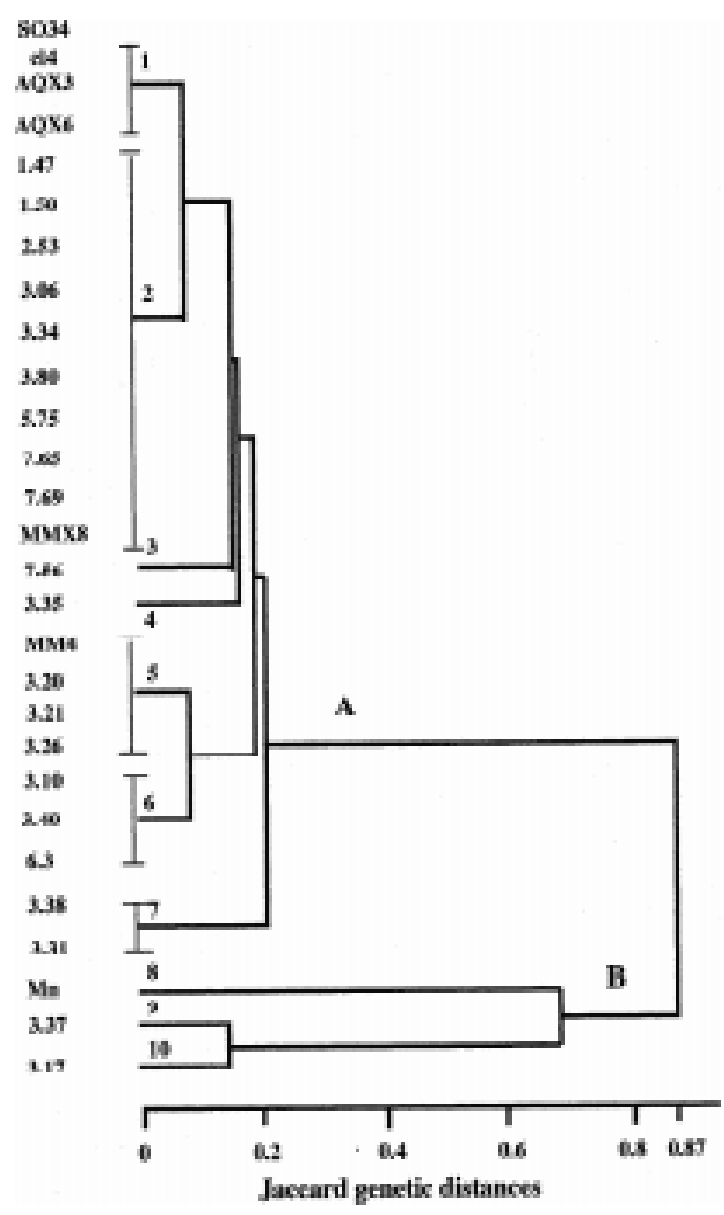

Fig. 2: UPGMA (unweighted pair group method of analysis) dendrogram derived from genetic Jaccard'distances obtained from multilocus enzyme electrophoresis (MLEE) of 25 Trypanosoma cruzi Peruvian stocks and two reference ones. 
TABLE III

Multilocus genotypes of 27 Trypanosoma cruzi Peruvian stocks and two reference stock

\begin{tabular}{|c|c|c|c|c|c|c|c|c|c|c|c|c|c|c|}
\hline Stock $^{a}$ & G6pd & Gpi & Gd nad & Gd nad + & $I d h$ & $M d h$ & $\mathrm{Mel}$ & $M e 2$ & Pepl & Pep2 & Pgm & $6 P g d$ & Got & Zymodemes \\
\hline $\begin{array}{l}\text { 1.47, 1.50, } 2.53 \\
3.06,3.34 \\
3.80,5.75,7.65 \\
\text { 7.69, } \mathrm{MMX}^{b}\end{array}$ & $2 / 2$ & $3 / 3$ & $3 / 3$ & $2 / 2$ & $1 / 1$ & $1 / 1$ & $2 / 2$ & $1 / 1$ & $2 / 2$ & $1 / 1$ & $1-4$ & $2 / 4$ & $2 / 2$ & 2 \\
\hline $3.10,6.3,3.40$ & $2 / 2$ & $3 / 3$ & $3 / 3$ & $1 / 1$ & $1 / 1$ & $1 / 1$ & $2 / 2$ & $1 / 1$ & $2 / 2$ & $1 / 1$ & $1-4$ & $2 / 4$ & $2 / 2$ & 6 \\
\hline $\begin{array}{c}3.20,3.21,3.26 \\
\text { MM4 }\end{array}$ & $2 / 2$ & $3 / 3$ & $3 / 3$ & $1 / 1$ & $1 / 1$ & $1 / 1$ & $2 / 2$ & $1 / 1$ & $2 / 2$ & $2 / 2$ & $1-4$ & $4 / 4$ & $2 / 2$ & 5 \\
\hline 3.35 & $2 / 2$ & $3 / 3$ & $3 / 3$ & $2 / 2$ & $1 / 1$ & $1 / 1$ & $2 / 2$ & $1 / 1$ & $2 / 2$ & $2 / 2$ & $1-4$ & $2 / 4$ & $2 / 2$ & 4 \\
\hline $3.31,3.38^{c}$ & $2 / 2$ & $3 / 3$ & $3 / 3$ & $2 / 2$ & $1 / 1$ & $1 / 1$ & $2 / 2$ & $1 / 1$ & $1 / 1$ & $1 / 1$ & $1-4$ & $2 / 4$ & $2 / 2$ & 7 \\
\hline 7.56 & $1 / 1$ & $3 / 3$ & $3 / 3$ & $2 / 2$ & $1 / 1$ & $1 / 1$ & $2 / 2$ & $1 / 1$ & $2 / 2$ & $1 / 1$ & $1-4$ & $2 / 4$ & $2 / 2$ & 3 \\
\hline $\begin{array}{l}\text { So34 cl4, } \\
\text { AQX3, AQX6 }\end{array}$ & $2 / 2$ & $3 / 3$ & $3 / 3$ & $2 / 2$ & $1 / 1$ & $1 / 1$ & $2 / 2$ & $1 / 1$ & $2 / 2$ & $1 / 1$ & $1-4$ & $4 / 4$ & $2 / 2$ & 1 \\
\hline 3.30, mixture & $2 / 2$ & $3 / 3$ & $3 / 3$ & $1 / 1$ & $1 / 1+2 / 2$ & $1 / 1$ & $2 / 2$ & $1 / 1$ & $2 / 2+3 / 3$ & $1 / 1$ & $1-4$ & $2 / 4$ & $1 / 1+2 / 2$ & $6+(9$ or 10$)$ \\
\hline 3.32, mixture & $2 / 2$ & $3 / 3$ & $1 / 1+3 / 3$ & $1 / 1$ & $1 / 1$ & $1 / 1$ & $2 / 2$ & $1 / 1$ & $2 / 2+3 / 3$ & $1 / 1$ & $1-4-6-7$ & $2 / 4$ & $1 / 1+2 / 2$ & $6+(9$ or 10$)$ \\
\hline 3.37 & $2 / 2$ & $2 / 2$ & $1 / 1$ & $1 / 1$ & $2 / 2$ & $1 / 1$ & $1 / 1$ & $2 / 2$ & $3 / 3$ & $2 / 2$ & $3-6-7$ & $4 / 4$ & $1 / 1$ & 9 \\
\hline 3.17 & $2 / 2$ & $2 / 2$ & $1 / 1$ & $2 / 2$ & $2 / 2$ & $1 / 1$ & $1 / 1$ & $2 / 2$ & $3 / 3$ & $2 / 2$ & $3-6-7$ & $4 / 4$ & $1 / 1$ & 10 \\
\hline $\mathrm{Mn}$ & $1 / 1$ & $1 / 2$ & $2 / 2$ & $2 / 2$ & $2 / 2$ & $1 / 1$ & $2 / 2$ & $2 / 2$ & $3 / 3$ & $2 / 2$ & $2-5$ & $1 / 3$ & $1 / 1$ & 8 \\
\hline
\end{tabular}

$a$ : the number stock are from Santa Rita de Siguas, the first number indicate the code of the house, both others the triatomine number; AQX3 and AQX6 are from two patients; MMX8 and MM4 are from Triatoma infestans of Moquegua department. So34 cl4 and Mn are reference stocks pertaining to clone 20 and 39 respectively (see Tibayrenc \& Ayala 1988); $b$ : the Gd NAD genotype not determined; $c$ : the 6 Pgd genotype not determined. 
patterns compatible with mixture of zymodemes as previously reported by Tibayrenc et al. (1986) and were excluded from genetic analysis when necessary.

The polymorphism rates (Table IV) in the entire Peruvian sample and in Santa Rita de Siguas were very high and similar. Surprising, we observed a very important polymorphism in the sample limited to the single house no. 3 . The clonal diversity measured by the index of Whittam, is important and maintained in the population originated from a single house; the probability to sample two different zymodemes in the population of house no. 3 is 0.92 (Table IV).

Population genetic analysis of parasites - Severe general deficit of heterozygotes is apparent in the entire sample and in the set of stocks from Santa de Rita de Siguas. Departures from HardyWeinberg expectations (segregation tests) were highly significant $(p<0.001)$ for glutamate dehydrogenase NADP+ locus. The H-W test was not applicable for other loci. Linkage disequilibrium statistics (recombination tests; see Tibayrenc et al. 1990) were highly significant in the entire sample and in the set of T. cruzi stocks from Santa Rita de Siguas (Table IV). In the population composed of the T. cruzi stocks isolated from bugs taken in the house no. 3 , we also observed significant tests of recombination (Table IV). In this population, under the null hypothesis of lack of departure from panmictic expectations, the probablility of recording the most abundant genotype with a size as high or higher than actually observed (4 stocks) was $<0.05$ (test $\mathrm{d} 1$ ); the probability of observing any genotype with a size as high or higher than the dominant genotype's one was $<0.05$ (test $\mathrm{d} 2$ ); the probablility of observing as few or fewer different genotypes than actually observed (7 zymodemes) was $<10^{-4}$ (test e); the probability of observing as high a linkage disequilibrium as actually observed was close to 0 (test $\mathrm{f}$ ).

Clustering - The UPGMA dendogram computed from Jaccard's distance matrix (Fig. 2) shown two clades (A and B) each composed of Peruvian isolates. Most of the Peruvian stocks were clustered together with SO34 cl4 reference stock (clone 20 ) and pertained to the clade A. Only two stocks, namely 3.37 and 3.17 were genetically very different, more related to $\mathrm{MN}$ reference stock (clone 39) and clustered in clade B; they were only sampled in the house no. 3 .

Spatial distribution of clones - Genotype 2 is the most frequently sampled in Santa Rita de Siguas. We studied its distribution among capture sites (houses) by $\mathrm{X}^{2}$. This genotype was significantly more abondant in the house no. 3 than in others of Santa Rita de Siguas $\left(X^{2}=7.71, d d l=1\right.$, $\mathrm{p}<0.01)$.

\section{DISCUSSION}

Genetic variability of vectors - This study realized in the province of Arequipa, Peru, allowed us to find two variable loci in $T$. infestans triatomines: $P g m$ and $6 P g d h$, whereas three different polymorphic loci were previously described in $T$. infestans species (Dujardin \& Tibayrenc 1985 a,b, Dujardin et al. 1987). T. infestans triatomines from Arequipa and Santa Rita de Siguas showed high genetic differences: while both $P g m$ and $6 P g d h$ loci were variable in Arequipa only Pgm locus was variable in Santa Rita de Siguas. This last result is consistent with a previous study realized 12 years before in the same area of Santa Rita de Siguas (Dujardin 1990). The presence of $T$. infestans triatomines in Arequipa, described for the first time in this study, is recently and confirmed by the local authorities of the Ministry of Health and the scientists of the University of Arequipa. The origin of T. infestans in Arequipa could derived in part from Santa Rita de Siguas, but the identification of allele 2 of $6 P g d$

TABLE IV

Population genetic analysis of Trypanosoma cruzi stocks

\begin{tabular}{|c|c|c|c|c|c|c|c|c|c|}
\hline \multirow[t]{2}{*}{$\begin{array}{l}\text { T. cruzi } \\
\text { populations }\end{array}$} & \multirow[t]{2}{*}{$\begin{array}{l}\text { Sample } \\
\text { size }\end{array}$} & \multirow[t]{2}{*}{$\begin{array}{l}\mathrm{P} \\
\text { rate }\end{array}$} & \multirow{2}{*}{$\begin{array}{c}\text { Number of } \\
\text { observed } \\
\text { genotypes }\end{array}$} & \multirow[t]{2}{*}{$\begin{array}{l}\text { Whittam } \\
\text { index }\end{array}$} & \multirow{2}{*}{$\begin{array}{l}\text { Efective of the } \\
\text { most commum } \\
\text { genotypes }\end{array}$} & \multicolumn{4}{|c|}{$\begin{array}{l}\text { Recombination tests } \\
\text { (p) }\end{array}$} \\
\hline & & & & & & d1 & $\mathrm{d} 2$ & $\mathrm{e}$ & f \\
\hline Entire Peruvian & 29 & 0.92 & 9 & 0.86 & 10 & 0.015 & $10-3$ & $<10-4$ & 0 \\
\hline Santa Rita de Siguas & 25 & 0.92 & 8 & 0.83 & 9 & 0.002 & $<10-4$ & $<10-4$ & 0 \\
\hline Stocks from & 17 & 0.83 & 7 & 0.92 & 4 & 0.018 & 0.018 & $<10-4$ & 0 \\
\hline
\end{tabular}

population B

(house no. 3)

P: polymorphism rate; $a$ : the mixed stocks have been counted as two stocks each; $b$ : probability to sample two different genotypes; $c$ : mixed stocks have been excluded. 
locus, found only in Arequipa triatomines, indicate a second origin; this allele 2 is also described in Bolivian populations (Dujardin 1990) and in southern Peruvian populations (unpublished data).

Genetic varability of parasites and clonality Among the Peruvian T. cruzi stocks under study we observed 9 different zymodemes clearly grouped in two principal clades A and B (Fig. 2). The 25 stocks pertaining to clade A were genetically related to those caracterized 12 years before (Brenière et al. 1985, 1991) by similar isoenzyme analysis using the same reference stocks as control, clone 20 and clone 39 (Tibayrenc \& Ayala 1988). Two other stocks pertaining to genotypes 9 and 10 were never described before in this region and were clustered in clade B.

Criteria of clonality have been extensively described by Tibayrenc et al. (1990). The present results agree with the hypothesis of clonality of $T$. cruzi population.

Two stocks isolated from $T$. infestans in Moquegua departement present the same genotype ( 2 and 5) than several stocks isolated in Santa Rita de Siguas. The fact that these areas are geographically distant confirms the ubiquitous character of T. cruzi zymodemes, one of the criteria of clonality (Tibayrenc et al. 1990).

The genetic segregation and recombination tests were mostly significant in the entire population and in the population of Santa Rita de Siguas. Significant segregation and recombination tests are also criteria for clonal structure of populations (Tibayrenc et al. 1990). Even though, reliability of $\mathrm{H}-\mathrm{W}$ test, depends on the diploid hypothesis of $T$. cruzi and is limited by small sample size, recombinant tests, independent of diploid hypothesis, give more unquestionable interpretation of the results.

Geographic partition of population (absence of sympatric conditions) is a potential source of significant tests even in sexual species. That can explain the significativity of the tests when populations of Santa Rita de Siguas and Arequipa are tested together and when the populations of the different houses in Santa Rita de Siguas are analyzed. However, the T. cruzi population isolated from a single house (no. 3 ) is sympatric and the recombination test are still significant.

The stocks isolated from house no. 3 are clustered in two separate clades (A and B, Fig. 2) and the recombinant tests performed on clade A (data not shown) were not significant. Therefore, the presence of two cryptic species cannot be excluded. The absence of significativity of the recombination tests could be related to the presence of two cryptic species either to bias due to the application of the tests to sub phylogenic division where ge- netic diversity is low.

Micro distribution of T. infestans genotypes and T. cruzi clones - The micro distribution of $T$. infestans genotypes and T. cruzi clones within individual houses of Santa Rita de Siguas indicate that house no. 3 differs from others for: (a) a higher density of insects in this house; (b) a greater infection rate of the triatomines; (c) a different $T$. cruzi clone distribution; and (d) differences in allelic frequencies of $T$. infestans.

Therefore, the dispersal capacity of $T$. infestans is very reduced and the panmictic unit appears to be smallest than the whole locality as previously proposed by Dujardin et al. (1985). The polymorphism rate evidenced by isoenzyme in $T$. infestans taxon is very low and limits the genetic interpretation of genetic flux between populations. New markers (eg. RAPD and microsatellite DNA) has to be developed to reach more resolutive approach. The absence of homogeneity in T. cruzi clone distribution between house no. 3 and the others confirm the separation of the insect populations.

\section{ACKNOWLEDGEMENT}

To Dr Jean-Pierre Dujardin (ORSTOM) for communication of the F statistic test and revising the manuscript. To Michel Tibayrenc (ORSTOM) for critical review of the manuscript which was helpful.

\section{REFERENCES}

Ben Abderrazak S, Guerrini F, Mathieu-Daudé F, Truc P, Neubauer K, Lewicka K, Barnabé C, Tibayrenc M 1993. Isoenzyme electrophoresis for pasasite characterization, 21, p. 361-382. In Methods in Molecular Biology, John E. Hyde Copyright, Human Press Inc, Totowa, NJ.

Bilton DT 1992. Genetic population structure of the postglacial relict diving beetle Hydroporus glabriusculus Aubé (Coleoptera : Dystiscidae). Heredity 69: 503511.

Brenière SF, Braquemond $\mathrm{P}$, Solari A, Agnèse JF, Tibayrenc M 1991. An isoenzyme study of Trypanosoma cruzi natural clones isolated from the two sides of the West Andes Highland. Trans R Soc Trop Med Hyg 85: 62-66.

Brenière SF, LLanos B, Tibayrenc M, Desjeux P 1985. Isoenzymic studies and epidemiological data of Trypanosoma cruzi from Arequipa (Peru), Pacific side. Ann Soc Belge Méd Trop 65: 63-66.

Dujardin JP 1990. Etude de quelques populations naturelles de Triatoma infestans. PHD in Sciences, Université de Paris VI, France, 194 pp.

Dujardin JP, Tibayrenc M 1985a. Etude de 11 enzymes et données de génétique formelle pour 19 loci enzymatiques chez Triatoma infestans (Hemiptera: Reduvidae). Ann Soc Belge Méd Trop 65: 271-280.

Dujardin JP, Tibayrenc M 1985b. Etude isoenzymatique du vecteur principal de la maladie de Chagas: Triatoma infestans (Hemiptera : Reduvidae). Ann Soc 
Belge Méd Trop 65: 165-169.

Dujardin JP, Tibayrenc M, Venegas L, Maldonado L, Desjeux P, Ayala FJ 1987. Isoenzyme evidence of lack of speciation between wild and domestic Triatoma infestans (Heteroptera: Reduviidae) in Bolivia. J Med Entomol 24: 40-45.

Godfrey DG, Kilgour V 1976. Enzyme electrophoresis in characterizing the causative agent of Gambian trypanosomiasis. Trans R Soc Trop Med Hyg 71: 217225.

Jaccard P 1908. Nouvelles recherches sur la distribution florale. Bull Soc Vaudoise de Sc Nat 44: 223-270.

Lanar DE, Levy LS, Manning JE 1981. Complexity and content of the DNA and RNA in Trypanosoma cruzi. Mol Biochem Parasitol 3: 327-341.

Lent H, Wygodzinsky P 1979. Revision of the Triatominae (Hemiptera, Reduviidae) and their significance as vectors of Chagas' disease. Bull Am Mus Nat Hist NY 163: 125-520.

Nei M 1987. Molecular evolutionary genetics. Columbian University Press, 512 pp.

Serres E, Roux M 1986. Pratique de la classification automatique: L'exemple des Leishmania, p. 27-40. In JA Rioux, Leishmania. Taxomomie et phylogénèse. IMEEE, Montpellier, France.

Sneath PHA, Sokal RR 1973. Numerical taxonomy. The principles and practice of numerical classification. In D Kennedy, RB Park (eds), Freeman and Company, San Francisco, 359 pp.

Tibayrenc M, Ayala FJ 1988. Isoenzyme variability in Trypanosoma cruzi, the agent of Chagas disease: genetical, taxonomical and epidemiological signifi- cance. Evolution 42: 277-292.

Tibayrenc M, Cariou ML, Solignac M 1981. Interprétation génétique de zymogrammes de flagellés des genres Trypanosoma et Leishmania. Comptes Rendus de l'Académie des Sciences, Paris 292: 623-625.

Tibayrenc M, Echalar L, Desjeux P 1982. Une méthode simple pour obtenir directement des isolats de Trypanosoma cruzi à partir du tube digestif du triatome vecteur. Cahiers ORSTOM, Série Entomol Méd Parasitol 20: 187-188.

Tibayrenc M, Kjellberg F, Ayala FJ 1990. A clonal theory of parasitic protozoa: the population structure of Entamoeba, Gardia, Leishmania, Naegleria, Plasmodium, Trichomonas and Trypanosoma, and its medical and taxonomical consequences. Proc Nat Acad Sci USA 87: 2414-2418.

Tibayrenc M, Hoffmann A, Poch O, Echalar L, Le Pont F, Lemesre JL, Desjeux P, Ayala FJ 1986. Additional data on Trypanosoma cruzi isozymic strains encountered in Bolivian domestic transmission cycles. Trans $R$ Soc Trop Med Hyg 80: 442-447.

Tibayrenc M, Kjellberg F, Arnaud J, Oury B, Brenière SF, Dardé ML, Ayala FJ 1991. Are eukaryotic microorganisms clonal or sexual? A population genetics vantage. Proc Nat Acad Sci USA 88: 5129-5133.

Whittam TS 1989. Clonal dynamics of Escherichia coli in its natural habitat. Antonie van Leeuwenhock 55: 23-32.

Workman PL, Niswander JD 1970. Populations studies on Southwestern Indian Tribes. II Local genetic differenciation in the Papago. Amer J Hum Genet 22: 24-49. 